\title{
Nested Pattern
}

National Cancer Institute

\section{Source}

National Cancer Institute. Nested Pattern. NCI Thesaurus. Code C35892.

A microscopic finding indicating that the neoplastic cells are arranged in compact nests in a tumor sample. 